\title{
Restricting Factors Analysis and Policy Study for the Innovation of Technology SMEs-Taking High-tech Industrial Development Zones of Taiyuan as an Example
}

\author{
Wen $\mathrm{ZHAO}^{\mathrm{a},{ }^{*}}$ and Ya-Hui LU ${ }^{\mathrm{b}}$ \\ College of Management Science and Engineering, Shanxi University of Finance \& Economics, \\ Taiyuan 030006, China \\ azhaowenteacher@126.com, ${ }^{\mathrm{b}} 1078842849 @ q q . c o m$ \\ "Corresponding author
}

Keywords: SMEs, Innovation, Leading talent, Innovation platform.

\begin{abstract}
Technology SMEs are of great significance for promoting the innovation and development of our country. This paper discusses the main factors restricting the innovation and development of SMEs through questionnaire survey, including lack of qualified personnel, lack of platform for innovation exchange, inability to obtain cutting-edge scientific and technological information, lack of funds and lack of strategic partners. In response to these Restricting factors, this paper puts forward some policy suggestions from the perspectives of introducing leading talents, giving play to the role of intermediary organization of CAST, improving the financing service system of SMEs and choosing the right strategic partner.
\end{abstract}

\section{Introduction}

Technology SMEs are an important part of the main body of market operation in China. Supporting and promoting the development of Technology SMEs is of great significance to promoting China's technological innovation and accelerating China's economic development from element-driven to innovation-driven. The report of 18th National Congress of the Communist Party of China clearly stated: "To support the development of small and micro enterprises, especially Technology SMEs." To this end, the state and local governments have introduced many supportive policies. However, the development of Technology SMEs is not easy and many enterprises can not grow strong or even die. Many scholars have analyzed the factors restricting the development of Technology SMEs from different perspectives [1,2,3]. However, because "innovation" is an important feature of Technology SMEs, this study focuses on improving the ability of innovation of Technology SMEs. Through in-depth field research and questionnaire surveys, this paper investigates the status of innovation and development of Technology SMEs, analysis the reasons of restricting the innovation and development of SMEs, so as to put forward ideas and programs to improve the technological innovation capability of enterprises and provide references for the innovation and development of technology SMEs.

\section{Restricting Factors Analysis for the Innovation of Technology SMEs}

Based on the literature review, this study summarizes 11 main factors restricting the innovation of technology SMEs (as shown on the horizontal axis in Figure 1). Subsequently, we selected four technology SMEs in Taiyuan High-tech Zone in Shanxi Province to conduct in-depth interviews to find new Restricting factors. The respondents indicated that the 11 listed factors covered the problems they encountered in innovation and development and the factors listed were comprehensive. Due to the different weights of 11 factors, in order to get the relative importance of each factor, this study distributed 110 questionnaires to technology SMEs in Taiyuan High-tech Zone, 103 questionnaires were recalled and all are valid questionnaires. 18 of them were collected through on-sit recycling, and the remaining questionnaires were collected through the website of "Questionnaire". We obtain the proportion of enterprises that select the influential factors and this 
proportion reflects the relative importance of the current factors that restrict the innovation and development of technology SMEs. The results are shown in Figure 1:

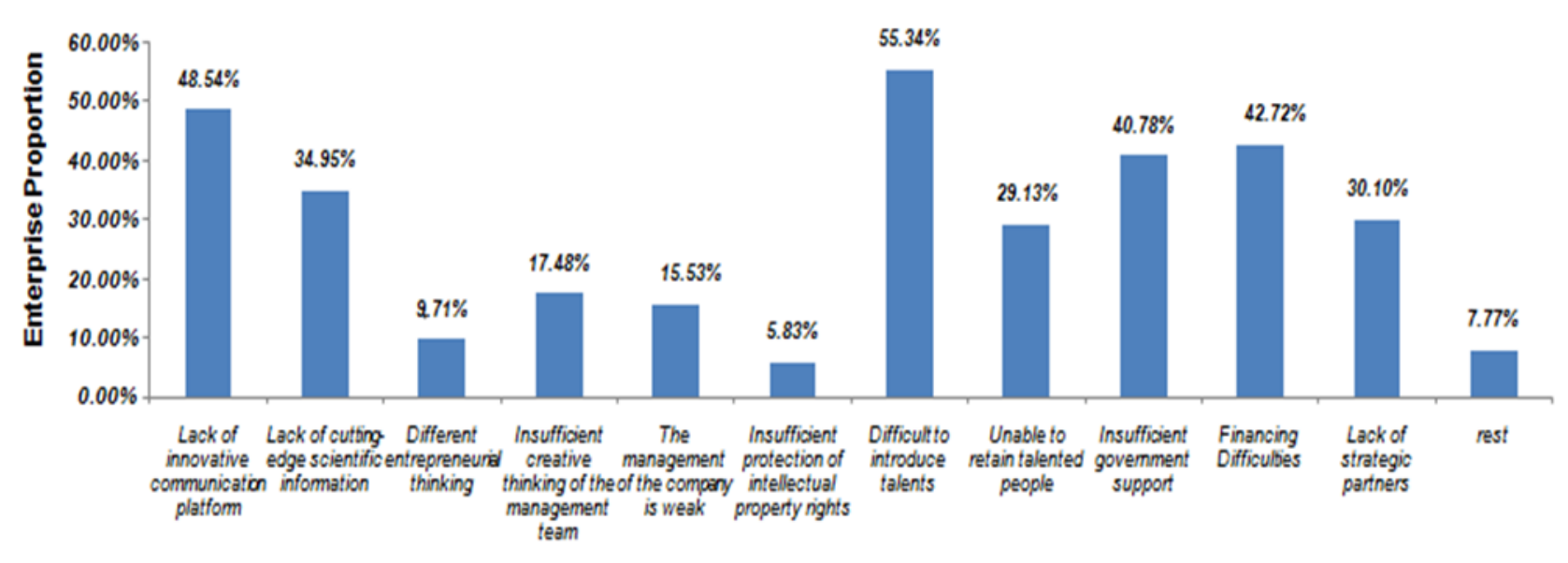

Fig. 1 The proportion of enterprises with the restrictive factors of innovation development

The figure is a bar chart of the main factors restricting the innovation and development of enterprises, the following will analyze the common constraints:

\section{Lack of Talent}

Talent is the most important resource for technology SMEs. Sample data show that the average number of researchers is 28 , only 14 enterprises have more than 10 employees with master's degree or above. Most enterprises have less than 5 employees with master's degree or above, and 16 enterprises do not even have employee with Master's degree or above. The per capita patent for scientific researchers is 0.47 .

An important reason for the shortage of qualified personnel is the difficulty in bringing in talented people. Among the samples, 55.34\% of the enterprises chose the difficulty in bringing in talented people as the main factor restricting the innovation and development of their enterprises, accounting for the highest proportion. Shanxi is located in the middle. Compared with the developed coastal cities in China, its economic development is relatively backward, so it is difficult to attract talented people. In addition, Shanxi is a coal-producing province with obvious resource curse effect. That is, the demand for all kinds of high-quality talents in coal-dominated industrial structure is not high. In this environment, outsiders have more negative impression about Shanxi. For example, "coal bosses", "safety accidents", "conservative" and so on are the major impression which are very detrimental to the introduction of high-level talent. In addition, $29.13 \%$ of the enterprises chose the inability to retain the talent people as the main factor. The reasons are: low pay, outdated management, external poor environment and limited development opportunities. On the one hand, it is difficult to bring in talents; on the other hand, it is difficult to retain talents. The combination of the two dilemmas has severely restricted the innovation and development of technology SMEs. It is an important breakthrough point for solving the innovation and development of technology SMEs to solve these two dilemmas.

\section{Lack of Innovative Exchange Platform and Have No Abundant Cutting-edge Scientific and Technological Information}

Innovative exchange platform and cutting-edge scientific and technological information is prerequisite for innovative activities of SMEs. Sample data shows that $48.54 \%$ of the enterprises indicated that the main factor restricting their innovation and development is lack of innovation exchange platform; $34.95 \%$ of the enterprises indicated that they have no abundant cutting-edge scientific and technological information. According to the results of the questionnaire "what service would you want to get in your enterprise technological innovation?", 62.14\% of enterprises indicated that they wanted to build a platform for technological innovation exchange. This shows 
that the platform for technological innovation exchange is crucial to technology SMEs. Most enterprises are eager to exchange outstanding innovative experiences and share cutting-edge scientific and technological information through this platform so as to promote the innovation ability of their enterprises. Most of the enterprises in Shanxi belong to the traditional enterprises, and they know relatively little about the latest innovation knowledge and frontier information. There are still some transformational enterprises which are in the initial stage. They need especially advanced innovative experience to guide them. In addition, there are many innovative incubators, which are small companies founded by young people, most of them are in the early stages of construction. They have less innovation experience and need excellent start-up mentors to help them to grow rapidly. In a word, many enterprises need the innovation information. But, traditional government websites provide less innovation information for enterprises and most of them are static news which leads to relatively little communication between the government and the enterprises. Unlike traditional government websites, science and technological exchange platforms can not only provide massive and practical static innovation information to SMEs, but also interact with SMEs to provide dynamic innovation information. Innovation and exchange platform should be a platform composed of various types of roles, including government, research institutes, colleges and universities, service agencies for innovation, all kinds of technology SMEs etc.

Sample data shows that $51.46 \%$ of enterprises want to get the "expert technical consultation". It is obvious that outstanding experts with innovative experience are indispensable for technological innovation enterprises. $47.96 \%$ of the enterprises indicated that their cooperation with colleges and universities is effective. $39.36 \%$ of the enterprises said that their cooperation with scientific research institutes is effective. Therefore, it is necessary to include universities and research institutes in the platform. Therefore, we can provide technology SMEs with a series of science and technology information by integrate fully these resources.

Sample data shows that $46.6 \%$ of enterprises indicated that they hope to get abundant scientific and technological information. Due to the constraints of multiple factors such as capital, equipment, technology and personnel, now the base information work of most enterprises in China is still lagging behind. Although some of the qualified enterprises have set up information service departments which are specialized in collecting, analyzing and researching intelligence information, their intelligence analysis techniques and methods are relatively laggard and they cannot provide deep-seated and comprehensive intelligence information.

\section{Insufficient Funds}

Capital is one of the important conditions for innovative activities of technology SMEs. As shown in the figure 2, 25.24\% of the enterprises said that it is more difficult to raise finance and $13.59 \%$ of the enterprises said it is very difficult. That means $38.83 \%$ of the enterprises have some obstacles in financing. In respect to the issue of "what are the main factors restricting the development of an enterprise?" $42.72 \%$ of the enterprises said that they were having difficulties in financing; $77.67 \%$ of enterprises expressed the hope of obtaining financial support on the issue of "what service does your enterprise want to get in the innovation process?" It can be inferred from these data that capital is an important factor restricting the innovation and development of technology SMEs. Here are the causes of hard financing: (1) the development capability and profitability of SMEs are relatively weak, which makes their endogenous financing impossible; (2) due to their small scale, low technical level and low reputation level, SMEs have poor access to external financing, especially bank loans. 


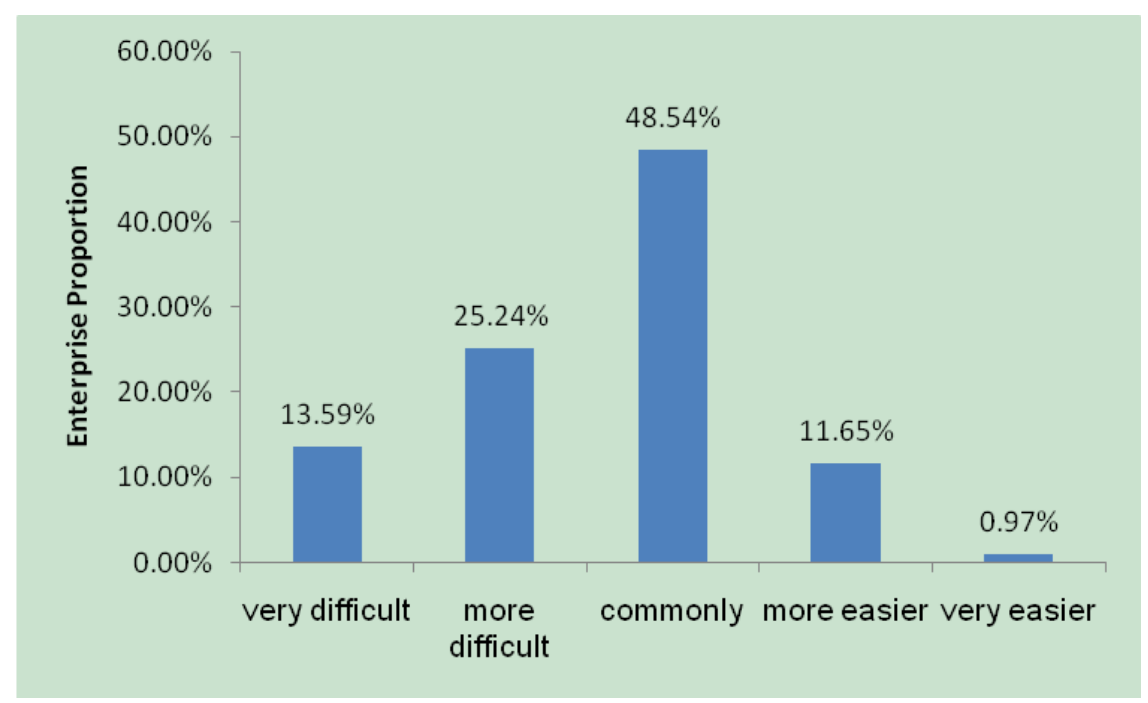

Fig. 2 The degree of financing difficulty perceived by enterprises

During the investigation, we further realized what enterprises want most from the government is financial support. According to the sample data, $40.78 \%$ of the enterprises indicated that one of the main factors restricting their innovation and development is the lack of government support. In addition to the limited financial resources, poor communication between enterprises and the government is another reason for the lack of government support. 59.22\% of the enterprises said that they did not know the access channel of government policy. 50.49\% of the enterprises indicated that they did not understand the policy thoroughly when they read the government policy, which lead to the enterprise can not enjoy the preferential tax policy.

\section{Lack of Strategic Partners}

To adapt to the complex market environment, enterprises must cooperate to obtain the resources they need. Sample data shows that $30.1 \%$ of enterprises said that one of the main factors restricting their technological innovation is lack of strategic partners. SMEs usually have less capital, lower specialization, smaller scale and output, so they are in a weak position when competing with large enterprises. Then implementing strategic alliance is an important way for SMEs to seek survival and development. Therefore, while giving full play to their own advantages, enterprises should actively look for cooperation enterprises that can make up their own disadvantages and help them to grow better. They can establish good cooperative relations with these enterprises and make full use of their strengths through cooperation. As a result, they can obtain the key resources needed for business development, reduce the risks in the operation of the market, especially reduce the risk of research and development, so as to improve their market competitiveness [4].

\section{Policy Study for the Innovation and Development of Technology SMEs}

In view of the above-mentioned major restricting factors on the innovation and development of technology SMEs, this study proposed the following countermeasures:

\section{Introduce in Leading Talent to Build a Talent Pool with Strategic Vision}

Birds of a feather flock together. Excellent people like to "get together", especially like to get together around the core talent. Leading talent is precious scarce resource, especially for science and technology SMEs, they are often the creators of new knowledge, inventor of new technologies, creators of new disciplines, leader and pioneer of breakthroughs in science and technology, as well as an organizer and leader of an innovative team [5]. Therefore, the region where is lack of talent should firstly introduce in the leading talent. In this process, we should pay attention to two aspects: First, make good use of leading talent. Although all kinds of "thousands of people plan" and "Hundred Talents Plan" have been promulgated in various places, due to the obscurity of knowledge, 
employers are required to fully tap the potential of the leading talent through various methods. Second, the construction of talent gathering place is a long-term process and systematic project. This requires that the regional policy should have a strategic vision, continuity and systematic, and not only be for temporary performance.

\section{Building Science and Technology Innovation Service Platform through CAST}

The China Association for Science and Technology (hereinafter referred to as CAST) is the bridge and link between the government and the technology workers in the park. It is an important platform for the cohesion of science and technology workers. It is an important force for promoting the scientific and technological progress of enterprises and promoting the innovation and development of enterprises. CAST should give full play to its own advantages, vigorously build science and technology innovation service platform, integrate maximally the industry resources, encourage universities, research institutes, enterprises, etc. to participate in co-building to reduce the market and economic risks of common technology research and development. The construction of innovative service platform should focus on innovation and entrepreneurship development, building a series of platforms such as business incubators platform, research and development platform, resource sharing platform, scientific and technological achievements transfer platform, domestic and foreign exchanges and cooperation platform. At the same time, CAST should actively explore new mode of innovative platform construction.

\section{Improve the Social Service System of SMEs' Financing}

We will encourage the establishment of regional policy banks to serve the financing of technology SMEs and increase their support for loans. At the same time, we will establish a policy-based guarantee agency to improve the credit rating system for technology SMEs, strengthen the cooperation between banks and enterprises, and establish a long-term mechanism of enterprise financing. Finally, communication channels between government and enterprises should be improved, so enterprises can not only obtain timely the information of government preferential policies, but also understand thoroughly the information. In this way, on the one hand, the government can guide the development of industries through preferential policies; on the other hand, it can also enable a large number of technology SMEs to obtain government funds to help the rapid development of these enterprises.

\section{Constructing the alliance Network with Strategic Partners}

From the above analysis we can see that it play a huge role in the development of technology SMEs to construct the alliance network with strategic partners. However, the most of technology SMEs in Shanxi Province have relatively weak performance in this area. There is less communication among enterprises and they have less cross-organizational learning awareness. Through the survey, this study learned that most enterprises are not very clear how to implement strategic alliances. This study suggests that alliances should be established among SMEs. Due to the instability of SMEs, the large enterprises have no full information about SMEs and so they cannot construct trust between them. Therefore, it is often difficult for SMEs to form alliances with large enterprises but easier with SMEs which have equal strength. The industrial cluster provides such a platform. In the industrial cluster area, a large number of SMEs are gathered together. They coordinated with each other, promoted each other, shared resources and complement each other. On the one hand, the competitiveness of SMEs in the cluster is greatly enhanced; on the other hand, it formed certain regional competitive advantages and played an important role in the development of regional economy.

\section{Acknowledgements}

This research was financially supported by the Shanxi soft science research project (Grant No. 2016041014-1), the Special Research Foundation of the Cooperative Innovation Center for Transition of Resource-based Economies (Grant No.2017317). 


\section{References}

[1] Kunhong DENG, Xiao ZHANG, Ping GAO, Li HE, Empirical Research on Promoting the Development of Small and Medium sized S\&T Enterprises in Hubei Province, J. Science and Technology Management Research. 22 (2015) 89 -94.

[2] Xiaobin FENG, Liqiong CHEN, Can External Knowledge Search Facilitate SMEs Synergistic Innovative Capability? An Empirical Study of the Mediating Role of Complementary Knowledge Integration and Supplementary Knowledge Integration, J. Science of Science and Management of Science and Technology. 08 (2015) 105 -117.

[3] Fulin ZHU, Qiuyan TAO, Xiaomei ZHU, Qin HE, Does Social Capital Intensity Lead to Different Performance of Innovation Performance and Enterprises Growth? - An Empirical Study Based on More than 200 Small and Micro Enterprises of Science and Technology in Beijing, J. Economic review. 05 (2016) 115-131.

[4] Feng LIN, Yan ZHANG, Study on Strategic Cooperation Network of Commercial SMEs, J. Business Research. 02 (2010) 49-51.

[5] Jin-Jin SU, Ying LI, Analysis of the Key Factors Affecting the Growth of Science and Technology Leading Talent — Based on Empirical Analysis of Tianjin Science and Technology Leading Talent, J. Science and Technology Management Research. 08 (2013) 83-86. 